Anthropol. Sci. 102(1), 13-22, 1994

\title{
Methods and Problems in Time Allocation Studies
}

\author{
KAZUHIRO SUDA \\ Faculty of Humanities, Hokkaigakuen University, Asahi- \\ machi, 4-1-40, Toyohira-ku, Sapporo 062, Japan.
}

Received December 10, 1992

\begin{abstract}
Time allocation studies provide basic information for understanding human adaptive mechanisms, and thus are especially useful in cross-cultural and inter-individual comparisons of behavioral patterns. Time allocation study methods are classified into three types: (1) "individual tracing," in which the researcher traces a subject person, recording the times at which he/she changes behaviors; (2) "observation at fixed spot," in which the researcher records all subjects'departures from and returns to a fixed spot; and (3) the "random spot-check," in which the researcher visits the subjects to observe their behaviors according to a randomly set schedule. Comparing the advantages and disadvantages of these methods and examining the reliability of inter-society comparison based mainly on my studies in Papua New Guinea communities, this paper aims to identify the most appropriate methods in time allocation studies.
\end{abstract}

Key Words: time allocation, methodologies in the field, ecological anthropology, cross-cultural comparison, inter-individual comparison

\section{INTRODUCTION}

In ecological anthropology, which aims to elucidate human adaptive mechanisms in relation to environmental settings, people's time allocation has been recognized as one of the most basic components. In particular, time allocation data are essential in understanding the division of labor by sex or age group and the labor cost of various subsistence activities. Nonetheless, the methodologies for time allocation studies have only rarely been examined (e.g., Gross, 1984; Mulder and Karo, 1985). This paper, based on reviews of previous time allocation studies in the literature and my own studies in a non-commercialized Kubor-speaking community and a semi-commercialized Kiwai-speaking community in Papua New Guinea, aims to methodologically examine the reliability of and problems with time allocation studies.

\section{METHODS IN TIME ALLOCATION STUDIES}

In the early days, self-registered diaries were sometimes used for the study of time budgets, for instance, among the horticultural Bemba by Richards (1939). 
When the subjects understand the purpose of the study and cooperate with the researcher(s), the self-registered diary is a useful tool for collecting time-budget data (see Kimura, 1992). However, ecological anthropologists and human ecologists prefer direct observation, which makes it possible to quantitatively measure time use. A variety of research frameworks have been developed. For example, in a study of the activity pattern of the hunting-gathering Asmat in Irian Jaya by Arsdale (1978), three-week records were analyzed according to the frequencies of each subject's dominant activity in three time units: morning, afternoon, and evening. In my judgment, the time budget revealed in that study was not sufficient, however, because of the lack of information about the overall time use pattern.

In general, despite the fact that the nature of time allocation data - when and how long the subject person's time is spent in various activities - is quite simple, data collection in the field is arduous. The well-designed time allocation methods can be categorized into three types: (1) the "individual-tracing" method, in which the researcher traces a subject person, recording continuously the times at which he/she changes behaviors: (2) the "observation at fixed spot" method, in which the researcher records all subjects' departures from and returns to a fixed spot, usually the entrance to the settlement; and (3) the "random spot-check" method, in which the researcher visits the subjects at random times and observes what they are doing at that moment.

\section{“Individual-Tracing" Method}

In the "Individual-tracing" method, the researcher traces a subject person and continuously records the times at which he/she changes behaviors. Theoretically, the times used for any activities, together with the spots where they are performed, are precisely recorded.

In this method, however, the researcher tends to disturb the subject because the observations are made from nearby. In some cases, the subject person may not behave as usual because he/she does not want the researcher to observe some of his/her activities. There are other ways in which the "usual" behavioral patterns are disturbed: when following a hunter, for example, the researcher often allows game to flee. Another unavoidable drawback is the limitation on the number of subjects studied, since a researcher can usually trace only one person at any moment.

For an analysis of the temporal structure of fishing activities among hand-line fishermen of Nasake Island in Japan, Ohtsuka (1972) recorded twenty fishermen's activities in detail, assisted by a colleague. In this case, the researcher's presence in the sea-going boat did not disturb the fishermen's activities because of their intimacy with the researchers and because of the nature of hand-line fishing. With the four-day time allocation data obtained by "observation at fixed spot" method and the registered data on the fishermen's daily catches for one year, Ohtsuka 
estimated their fishing efficiency and its inter-individual variation. Kuchikura (1988) observed blowpipe hunting among the Semaq Beri in Peninsular Malaysia. He followed 58 trips and recorded the activities in detail. Based on these records, he calculated hunting efficiencies. In this case also, because of the nature of blowpipe hunting behavior, the researcher's existence seldom disturbed the hunters.

\section{"Observation at Fixed Spot" Method}

"Observation at a fixed spot" means that the researcher keeps watch on a number of persons - usually all persons (or all persons except children) within a community - at a fixed spot, records their times of departure from and return to it, and asks about the places where they have stayed outside the community.

This method has some disadvantages. First, the researcher cannot record times in activity spots away from the observation post. Second, the researcher must be stationed at the fixed observation spot throughout the day throughout the duration of the survey, and consequently cannot conduct other investigations. These constitute the difficulties of continuously gathering data over a long period.

However, there are some advantages in this method. Because all members (or all adult members) of a target community are usually studied, sampling is not needed. The researcher can construct time budgets for all community members and examine individual variations by sex, age, and other characteristics. For examples, detailed input-output analyses of subsistence activities have been achieved among the hunting-gathering !Kung San (Lee, 1968), and certain fishing communities (Suda, 1987; Ohtsuka, 1972) in which all subjects passed the same spot on the way to their work places.

\section{"Random Spot-Check" Method}

Data obtained by the "random spot-check" method have been considered the most reliable. In this method, the researcher visits randomly selected subjects at random times on randomly selected days, and observes what they are doing at the moment.

Erasmus (1955) first utilized this method in his study among the Mayo of Sonora in Mexico; his subjects were 200 individuals in 32 households, and his observations totaled 5,000 during a three-month study period. His pioneering work based on "random spot-checking" was ignored for 20 years, but this method has been recognized as useful in time allocation studies since Johnson's (1975) well-designed study among the Machiguenga in Peru. He studied 105 individuals of 13 households for a 14-month period (134 days); total observations numbered 3,495, for which hours were selected in advance with a table of random numbers, and households were visited during the hour specified in daytime between 6:00 and 19:00.

There are three major advantages in the "random spot-check" method. First, this method avoids biases caused by sampling. Second, since the time spent for this 
investigation is only one hour or so per day, the researcher can allocate time for other studies. Third, it is possible for the researcher to continuously collect data over a long period.

One of the possible disadvantages of the "random spot-check" method is in the difficulty of assigning the duration of time spent on each activity. However, Johnson estimated the time use pattern from the proportions of time used in each activity type by multiplying by 13 hours (6:00 to $19: 00)$.

Despite the several advantages of Jonhson's "random spot-check" method, many research projects have great difficulty in utilizing it because of the necessity of being stationed year-round in the target community and the need for checks on activity in as many as half or more of the total number of survey days. To solve this problem, Moji and Koyama (1985) developed the "time-saving spot-check" method in their study among a Sundanese peasant community in west Java. T'.ey randomly visited all members of a target community nine times at 90-minute intervals between 5:00 and 18:30 during four successive days, in the dry season and the wet season, accumulating 1,944 and 1,872 observations, respectively. In the "time-saving spotcheck" method a large number of data are collected over a short period, so it is possible to survey on different occasions, and thus inter-season differences are easily revealed.

Some researchers have pointed out the importance of investigating nighttime activities. Though all of the methods for time allocation studies have usually been applied to daytime activities (Gross, 1984), Scaglion (1986) observed nighttime activities among the Samukundi Abelam in Papua New Guinea, using the "random spot-check" method. As a result, he suggested the necessity of modifying sampling design for this purpose.

\section{Comparability of Data from Different Societies}

In examining the literature on determining whether labor time has increased in the transition from agricultural societies to industrial societies, Minge-Klevana (1980) revealed that there was a markedly wide range of labor time among the agricultural societies compared, and suggested that this was mostly attributable to differences in the data-gathering methods applied.

Her point is apparently correct; in a wider sense, the time allocation data obtained with different methods are difficult to compare because of the nature of the three types of methodology, as mentioned above. In my judgment, inter-society comparison of time allocation data is less meaningful unless the same method is applied. One effective way of comparing different societies (or communities) is for a single researcher or group of researchers to use the same method. For example, Ohtsuka and his colleagues conducted "observation at fixed spot" time allocation studies among four Gidra-speaking villages in Papua New Guinea (Ohtsuka, 1990), and 
found remarkable differences in time budgeted for subsistence activities among the villages according to the different microenvitonmental conditions and different degrees of permeation of the cash economy.

The comparison of time allocation data collected by different researchers in different societies is beneficial for cross-cultural studies. For this purpose, there are some problems to be solved even if the same methodology, whether "random spotcheck," "observation at fixed spot," or "individual-tracing," is applied. In particular, the coding system for activities tends to differ from one study to another, and this makes it difficult to compare the time allocation data. One way of overcoming this difficulty is for the researcher to break down time allocation data into as detailed a set of categories as possible. With these notions in mind, I will give an example of inter-society comparison below, using four data sets for Papua New Guinea societies; two of them were collected by me, and two others were separately collected by two other researchers.

\section{A CASE OF COMPARISON AMONG FOUR SOCIETIES}

Four Papua New Guinea societies, for which time allocation data are compared, are located in different environments: the Kubor in the foothills of the Great Papuan Plateau, the Kiwai on the coast, and the Yamiyufa and the Tairora in the highland. The former two groups were studied by myself, the Yamiyufa by Sexton (1980), and the Tairora by Grossman (1984).

\section{The Kubor and the Kiwai}

The Kubor, who had maintained a semi-nomadic lifestyle (Dwyer and Minnegal, 1991, 1992), settled in permanent villages in the 1970s. Their most important subsistence food has been the plantain banana; the second most important, Metroxylon sago starch (Suda, 1990, 1992). My study village, called Siuhamason, was inhabited by 108 persons of 29 households in 1988. The Kiwai have inhabited the coast and islands, subsisting on fishing, hunting, and banana and taro horticulture (Landtman, 1927). Because of their relatively early contact with the colonial government, they began cash-earning activities several decades ago, and since 1990 trepang gathering has become an important activity for earning cash. The study village, called Mawata, was inhabited by 118 persons of 17 households in 1990 .

For the above two field investigations, I judged that the "random spot-check" method was preferable, first because this method had been applied to many other societies, facilitating inter-society comparison, and second because in both villages, Siuhamason in the Kubor and Mawata in the Kiwai, the houses were congregated and thus my visits to the subjects were easy. The total duration of my study, i.e., several months in each survey, was not suited to Johnson's year-round "spot-check" method, so the "time-saving spot-check" method was applied. 
My research design was as follows: my visits were made in the daytime between 6:00 and 19:00, and each subject was visited 13 times per week. All adult and adolescent villagers, numbering 65 in the Kubor-speaking village and 67 in the Kiwai-speaking village, were studied. The study, based on the "time-saving spotcheck" method, was conducted for 7 successive days in July and 14 successive days in November among the Kubor, and for 6 successive days in September among the Kiwai; the total number of spot-check observations amounted to 2,535 and 871, respectively.

The results are shown in Table 1 for the Kubor and in Table 2 for the Kiwai. Because of the activity patterns, age-grouping differed between the societies, and the categorization of activities varied. The detailed sex/age differences of activity patterns in each society can be related to the people's different adaptive mechanisms (Suda, 1992, 1993), but are beyond the scope of this paper. It can be pointed out here that the sex difference in time use was smaller among the non-commercialized Kubor and larger among the Kiwai, particularly as seen in the trend toward males spending more time in cash-earning (e.g., fishing for trepang and trepang processing) and females spending more time in subsistence activities (e.g., horticulture).

Table 1. Percent time allocated to activities by age class and sex in the Kubor-speaking Siuhamason village (from 6:00 to $19: 00$ )

\begin{tabular}{lccccc}
\hline & \multicolumn{2}{c}{ Male } & & \multicolumn{2}{c}{ Female } \\
\cline { 2 - 3 } \cline { 5 - 6 } Youth & Adult & & Youth & Adult \\
Activity & $(\mathrm{N}=2)$ & $(\mathrm{N}=30)$ & & $(\mathrm{N}=3)$ & $(\mathrm{N}=30)$ \\
\hline Horticulture & 12.1 & 5.7 & & 8.5 & 7.6 \\
Sago-making & 0.0 & 2.0 & & 4.6 & 15.8 \\
Poultry & 0.0 & 0.3 & & 0.0 & 1.1 \\
Hunting & 9.9 & 17.9 & & 0.0 & 0.0 \\
Fishing & 4.4 & 0.8 & & 3.0 & 2.7 \\
Gathering & 0.0 & 0.9 & & 10.8 & 9.6 \\
Construction & 6.6 & 6.1 & & 0.8 & 1.6 \\
Tool-making & 1.1 & 0.9 & & 3.1 & 2.3 \\
Household maintenance & 3.3 & 2.6 & & 1.6 & 6.7 \\
Food preparation & 4.4 & 4.6 & & 4.6 & 5.9 \\
Eating & 3.3 & 3.8 & & 4.6 & 3.8 \\
Hygiene & 2.2 & 3.3 & & 0.8 & 2.2 \\
Illness & 0.0 & 0.6 & & 1.5 & 1.8 \\
Church & 3.3 & 4.8 & & 0.0 & 4.7 \\
Visiting & 8.8 & 22.1 & & 24.6 & 16.1 \\
Idleness & 39.6 & 22.5 & & 30.8 & 17.8 \\
Other & 1.1 & 1.1 & 0.8 & 0.2 \\
\hline
\end{tabular}


Table 2. Percent time allocated to activities by age class and sex in the Kubor-speaking Mawata village (from 6:00 to 19:00)

\begin{tabular}{|c|c|c|c|c|c|c|}
\hline \multirow[b]{2}{*}{ Activity } & \multicolumn{3}{|c|}{ Male } & \multicolumn{3}{|c|}{ Female } \\
\hline & $\begin{array}{l}\text { Unmarried } \\
\qquad(\mathrm{N}=8)\end{array}$ & $\begin{array}{l}\text { Married } \\
(\mathrm{N}=15)\end{array}$ & $\begin{array}{c}\text { Old } \\
(\mathrm{N}=10)\end{array}$ & $\begin{array}{l}\text { Unmarried } \\
\qquad(\mathrm{N}=8)\end{array}$ & $\begin{array}{l}\text { Married } \\
(\mathrm{N}=14)\end{array}$ & $\begin{array}{c}\text { Old } \\
(\mathrm{N}=12)\end{array}$ \\
\hline Horticulture & 1.0 & 6.2 & 14.6 & 12.5 & 9.9 & 21.2 \\
\hline Coconut harvesting & 7.7 & 0.5 & 1.5 & 3.8 & 0.6 & 1.9 \\
\hline Fishing & 2.9 & 7.7 & 13.1 & 1.9 & 0.6 & 1.3 \\
\hline Hunting & 1.9 & 1.5 & 0.8 & 0.0 & 0.0 & 0.0 \\
\hline Trepang processing & 7.7 & 10.3 & 9.2 & 5.8 & 8.2 & 4.5 \\
\hline Tool-making & 1.0 & 0.5 & 0.8 & 0.0 & 1.6 & 6.4 \\
\hline Household maintenance & 6.7 & 6.2 & 3.8 & 8.7 & 22.0 & 9.6 \\
\hline Food preparation & 1.0 & 3.1 & 3.1 & 9.6 & 10.4 & 10.2 \\
\hline Eating & 1.9 & 5.6 & 3.1 & 5.8 & 5.5 & 2.6 \\
\hline Hygiene & 1.0 & 0.5 & 4.6 & 3.8 & 4.4 & 2.6 \\
\hline Visiting & 6.7 & 22.0 & 8.5 & 14.4 & 6.0 & 9.0 \\
\hline Idleness & 59.5 & 35.9 & 34.6 & 32.7 & 30.2 & 27.5 \\
\hline Other & 1.0 & 0.0 & 2.3 & 1.0 & 0.6 & 3.2 \\
\hline
\end{tabular}

\section{Two highland societies}

Time allocations in two highland societies were studied by the Johnson's "random spot-check" method: the Yamiyufa by Sexton (1980) and the Tairora by Grossman (1984). The Yamiyufa have planted coffee as a cash crop since the 1950s, and the Tairora have planted coffee and raised cattle since the 1960s.

The time allocation data for these two highland societies could be compared with those in the Kubor and the Kiwai because of the application of "random spot-check" method or its "time-saving" variation. Furthermore, the economic and ecological conditions of the two highland societies which had accepted cash-earning activities were most useful for assessing the impact of the introduction of a cash economy in traditional societies, which has been one of the major current themes in ecological anthropology in Papua New Guinea (Suda, 1993). It can also be pointed out that in the time allocation data for these two societies, their activities were divided into minute categories; this makes it possible to compare them with other societies' data in detail.

\section{Inter-society comparison}

As suggested by my own data from two societies (Tables 1 and 2), the categorization of human activities into larger groups is necessary for inter-society comparison. Here, consulting with the previous categorizations (e.g., Johnson, 1975) on the one hand and considering the importance of the impact of a cash economy on the other, all activities in the four societies were grouped into four categories: 
"subsistence" (including all non-commercialized activities such as obtaining food, house maintenance, etc.), "cash earning," "leisure" (including rest, chatting, sleep, etc.) and "others" (including ritual, social, and religious activities) (Table 3). All data sets for the four societies described each activity in detail so that it was possible to categorize all activities as one of the above four types.

There are four major observations in Table 3. First, the proportion of males' time spent in subsistence activities (49.0\%) in the Kubor strikingly differs from that of the other three societies, $19.4 \%$ in the Yamiyufa, $31.4 \%$ in the Tairora, and $28.2 \%$ in the Kiwai. Second, the proportion of males' time spent in cash-earning activities showed the opposite pattern among the four societies. Third, the proportion of males' time spent on non-productive activities, i.e., leisure and "others" combined, in the Yamiyufa, Tairora, and Kiwai was $65.1 \%, 55.0 \%$, and $58.3 \%$, considerably higher than that of the Kubor, i.e., $48.9 \%$. Fourth, despite the fact that the proportion of females' time spent in productive activities (i.e., subsistence and cash-earning activities combined) among the Kubor (58.9\%) was comparable with that in the other three societies $(54.9 \%$ in the Yamiyufa, $63.7 \%$ in the Tairora, and $55.9 \%$ in the Kiwai), the proportion of females' cash-earning activities only was markedly lower for the Kubor females (1.3\%) than for the other three $(10.0 \%, 10.7 \%$, and $6.3 \%$, respectively).

These observations indicate that time allocation data provide us with a quantitative basis for inter-society comparison of behavioral pattern and lifestyle. In the above-mentioned comparison, the influence of involvement in the cash economy and the differences in that involvement between males and females were disclosed; these inter-society differences are the most basic ecological conditions for comparative analyses of human adaptation.

Table 3. Percent time allocated to four activity categories of adult males and females in four Papua New Guinea Societies

\begin{tabular}{|c|c|c|c|c|c|c|c|c|}
\hline \multirow[b]{2}{*}{$\begin{array}{l}\text { Activity } \\
\text { type }\end{array}$} & \multicolumn{2}{|c|}{ Yamiyufa') } & \multicolumn{2}{|c|}{ Tairora' ${ }^{2)}$} & \multicolumn{2}{|c|}{ Kubor $^{3)}$} & \multicolumn{2}{|c|}{ Kiwai ${ }^{3)}$} \\
\hline & $\begin{array}{c}\text { male } \\
(\mathrm{N}=19)\end{array}$ & $\begin{array}{l}\text { female } \\
(\mathrm{N}=22)\end{array}$ & $\begin{array}{c}\text { male } \\
(\mathrm{N}=14)\end{array}$ & $\begin{array}{l}\text { female } \\
(\mathrm{N}=16)\end{array}$ & $\begin{array}{c}\text { male } \\
(\mathrm{N}=32)\end{array}$ & $\begin{array}{l}\text { female } \\
(\mathrm{N}=33)\end{array}$ & $\begin{array}{c}\text { male } \\
(\mathrm{N}=33)\end{array}$ & $\begin{array}{l}\text { female } \\
(\mathrm{N}=34)\end{array}$ \\
\hline Subsistence & 19.4 & 44.9 & 31.4 & 53.0 & 49.0 & 57.6 & 28.2 & 49.6 \\
\hline Cash earning & 15.5 & 10.0 & 13.6 & 10.7 & 2.1 & 1.3 & 13.5 & 6.3 \\
\hline Leisure & 44.6 & 32.2 & 43.2 & 29.8 & 39.4 & 32.4 & 55.5 & 38.9 \\
\hline Other & 20.5 & 12.9 & 11.8 & 6.5 & 9.5 & 8.7 & 2.8 & 5.2 \\
\hline
\end{tabular}

1): Sexton (1980)

2): Grossman (1984)

3): the present author 


\section{CONCLUSION}

As noted above, it is possible to make inter-society comparisons of time allocation data obtained with the "random spot-check" method or its "time-saving" variation, although for this purpose it is preferable (and sometimes indispensable) for the researcher to report a large number of categories of activities in which the subject persons' time was spent and their implications. Taking into account methodological convenience as well, it can be judged that the "random spot-check" method is most useful for cross-cultural comparison.

There remain problems in exploring inter-individual variation of time allocation within the same community and labor efficiencies of different activities, mainly because the "random spot-check" method does not provide information on how activities are actually performed or on time duration of each activity. For these purposes, the "individual-tracing" and "observation at fixed spot" methods are more effective, even though it is difficult to collect large amounts of data. Thus, it is concluded that the "random spot-check" method is preferable for time allocation studies but that simultaneously "individual tracing" and "observation at fixed spot" methods should be applied for specific purposes.

\section{ACKNOWLEDGEMENTS}

I am deeply indebted to Dr. K. Moji for his valuable suggestions on the methodologies in time allocation studies, and to Dr. R. Ohtsuka for comments on the manuscript. This paper was presented at the symposium "Methodologies of ecological field surveys" (organizers: Dr. R. Ohtsuka and Dr. Y. Kuchikura), held at the 46th Meeting of the Anthropological Society of Nippon and the Japanese Society of Ethnology; my thanks go to the organizers and to the other participants, Dr. H. Terashima and Dr. T. Inaoka.

\section{REFERENCES}

Arsdale, P.W. (1978) Activity patterns of Asmat hunter-gatherers: A time budget analysis. Mankind 11, 453-460.

Dwyer, P.D., and Minnegal, M. (1991) Hunting in lowland tropical rainforest: Towards a model of non-agricultural subsistence. Hum. Ecol. 19, 187-212.

Dwyer, P.D., and Minnegal, M. (1992) Ecology and community dynamics of Kubo people in the tropical lowlands of Papua New Guinea. Hum. Ecol. 20, 21-55.

Erasmus, C.J. (1975) Work patterns in a Mayo village. Am. Anthropol. 57, 322-333.

Grossman, L.S. (1984) Peasants, Subsistence Ecology, and Development in the Highland of Papua New Guinea, Princeton Univ. Press, Princeton, New Jersey.

Johnson, A. (1975) Time allocation in Machiguenga community. Ethnology 14, 301-310.

Kimura, D. (1992) Daily activities and social association of the Bongando in central Zaire. African Study Monographs 13, 1-33.

Kuchikura, Y. (1988) Efficiency and focus of blowpipe hunting among Semaq Beri hunter-gatherers of Peninsular Malaysia. Hum. Ecol. 16, 271-305. 
Landtman, G. (1927) The Kiwai Papuans of British New Guinea, Macmillan, London.

Lee, R. (1968) What hunters do for a living, or, how to make out on scarce resources. In Man the Hunter (Lee, R., and DeVore, I., eds.), Aldine, Chicago, pp. 30-48.

Minge-Klevana, W. (1980) Does labor time decrease with industrialization? Curr. Anthropol. 21, 279-298.

Moji, K., and Koyama, H. (1985) A time-saving spot-check method applied to a Sundanese peasant community in west Java. Man Cul. Oceania 1, 121-127.

Mulder, M.B., and Karo, T.M. (1985) The use of quantitative observational techniques in anthropology. Curr. Anthropol. 26, 323-335.

Ohtsuka, R. (1972) Fishing time and catches among hand-line fishermen with special reference to individual variation and the relationship between fishing activity and natural environment. J. Hum. Ergol. 1, 3-18.

Ohtsuka, R. (1990) Time allocation for food procurement. In Population Ecology of Human Survival (Ohtsuka, R., and Suzuki, T., eds.), Univ. of Tokyo Press, Tokyo, pp. 15-22.

Richards, A.I. (1939) Land, Labour and Diet in Northern Rhodesia, 2nd Ed., Oxford Univ. Press, London.

Scaglion R. (1986) The importance of nighttime observations in time allocation. Am. Ethnol. 13, 537-545.

Sexton, L. (1986) Mothers of Money, Daughters of Coffee: The Wok Meri Movement, UMI Research Press, Ann Arbor.

Suda, K. (1987) Fishing activities after herring had left: Choices of Yagishiri fishermen. Quart. Anthropol. 18, 173-218. (In Japanese)

Suda, K. (1990) Leveling mechanisms in a recently relocated Kubor village, Papua New Guinea: A socio-behavioral analysis of sago-making. Man Cul. Oceania 6, 99-112.

Suda, K. (1992) Sago-making of Kubor village in Papua New Guinea. Sago Communication 3, 1-8. (In Japanese)

Suda, K. (1993) Socioeconomic changes of production and consumption in Papua New Guinea societies. Man Cul. Oceania 9, 69-79. 